\title{
News
}

\section{World HEAlth ORganization REPORTS HIghest RATES OF DRUG-RESISTANT TUBERCULOSIS TO DATE}

\author{
Editorial team (eurosurveillance@ecdc.europa.eu) ${ }^{1}$ \\ 1. European Centre for Disease Prevention and Control (ECDC), Stockholm, Sweden
}

On 26 February 2008, the World Health Organization (WHO) published its fourth report on the global situation regarding drug resistance in tuberculosis (TB) [1]. The report, based on information collected between 2002 and 2006 on 90,000 TB patients in 81 countries, found that $5.3 \%$ of the nine million new cases of TB each year are multidrug-resistant (MDR). This is the highest rate yet recorded.

The prevalence of MDR TB among new cases ranged from $2.8 \%$ in Romania to $22.3 \%$ in Baku, Azerbaijan. High proportions of resistance were also estimated in China, India and the Russian Federation. For the first time, data on extensively drug-resistant (XDR) TB were available from 35 countries, of which 25 were European. In total, data were given for 4,012 MDR TB cases, among which 301 (7\%) XDR TB cases were detected. In general, absolute numbers of XDR TB cases were low in Central and Western Europe, the Americas and in the Asian countries that reported data. The proportion of XDR TB among MDR TB in these settings varied from $0 \%$ in 11 countries to $30.0 \%$ in Japan. As these countries have a relatively low MDR TB burden, this represents few absolute cases. According to the report, the situation appears much more serious in countries of the former Soviet Union. In nine such countries that reported, approximately $10 \%$ of all MDR TB cases were XDR, but represented a much larger absolute number of cases.

\section{References}

1. The World Health Organization/International Union Against TB and Lung Disease Global Project on Anti-Tuberculosis Drug Resistance Surveillance. Anti-Tuberculosis Drug Resistance In The World: Fourth Global Report. Geneva; 2008. Report No.: WHO/HTM/TB/2008.394. Available from: http://www.who.int/ tb/publications/2008/drs_report4_26feb08.pdf

This article was published on 18 March 2008.

Citation style for this article: Editorial team. World Health Organization reports highest rates of drug-resistant tuberculosis to date. Euro Surveill. 2008;13(12):pii=8077. Available online: http://www.eurosurveillance.org/ViewArticle.aspx?ArticleId =8077 